\title{
Characterization of Bread Enriched with Jerusalem Artichoke Powder Content
}

\author{
Ana M Radovanovic ${ }^{1, *}$, Olivera Z Milovanovic ${ }^{1}$, Mihailo Z Kipic ${ }^{1}$, Milica B Ninkovic ${ }^{2}$, Snezana M Cupara ${ }^{1}$ \\ ${ }^{1}$ Faculty of Medical Sciences, University of Kragujevac, Serbia \\ ${ }^{2}$ Medical Faculty of Military Medical Academy, Belgrade, Serbia \\ *Corresponding author: ana.radovanovic@medf.kg.ac.rs
}

Received July 16, 2014; Revised October 28, 2014; Accepted November 07, 2014

\begin{abstract}
Helianthus tuberosus L. (Jerusalem artichoke) tubers are good source of dietary fiber (inulin) due to which are beneficial to human health. The objective of this study was to characterize wheat bread enriched with content of Jerusalem artichoke powder by organoleptic properties, nutritional and caloric value, microbiological safety, glycemic index (GI) and glycemic load (GL). The bread was made from yeast dough of the following content: $75 \%$ of wheat flour and $25 \%$ of Jerusalem artichoke powder. Glycemic index and load were determined according to the FAO/WHO protocol. The bread contained $41.64 \%$ of water, $58.36 \%$ of dry matter, $0.27 \%$ of lipids, $8.25 \%$ of proteins, $47.64 \%$ of carbohydrates, and $6.15 \%$ of dietary fiber. Caloric value of was $226 \mathrm{Kcal} / 100 \mathrm{~g}$ of bread. The glycemic index was 53.70, while glycemic load value was 7.67. The bread enriched with J. artichoke powder showed optimal nutritional and caloric value, low glycemic index and low glycemic load values.
\end{abstract}

Keywords: Jerusalem artichoke, nutritional value, glycemic index, glycemic load

Cite This Article: Ana M Radovanovic, Olivera Z Milovanovic, Mihailo Z Kipic, Milica B Ninkovic, and Snezana M Cupara, "Characterization of Bread Enriched with Jerusalem Artichoke Powder Content." Journal of Food and Nutrition Research, vol. 2, no. 12 (2014): 895-898. doi: 10.12691/jfnr-2-12-6.

\section{Introduction}

Helianthus tuberosus L. (known as Jerusalem artichoke) originates from north central part of the USA and belongs to the genus Helianthus, family Asteraceae [1]. It grows also in Serbia, as a native species known under the local name chichoka. J. artichoke tubers have specific chemical composition - $80 \%$ water, $15 \%$ carbohydrate, $1-2 \%$ protein, mono and poly-unsaturated fatty acids present in trace amounts [1]. The tubers are good source of vitamins (C, B and $\beta$-carotene), minerals (iron, potassium, calcium, sodium, selenium) and dietary fiber because of the presence of inulin $[2,3]$. Inulin content ranges from 8 to $21 \%$ in fresh tubers [1]. Inulin, as a mixture of linear $\beta$ (12 -linked fructose chains with one terminal unit of glucose $\alpha-(1-2)$ linked, is a soluble dietary fiber and has low caloricity [4]. It was shown that inulin-containing food is beneficial for human health - it promotes gastrointestinal healthy flora and mineral absorption from colon, which has been linked to prevention and alleviation of the osteoporosis progression [5,6,7]. Acting as a prebiotic, inulin stimulates activity of bacterial microflora and promotes digestive health [8]. Considering that inulin does not affect insulin level, since it does not get absorbed and digested in the small intestine, it could be useful in diet of diabetic patients [9]. These unique characteristics classify inulin as a functional food ingredient [10]. Health benefits of high-level dietary fiber diet induce interest for new applications of low-digestible carbohydrates (LDC) ingredients. Food formulations with inulin can improve the nutritional value of the end product by increasing the dietary fiber content, reducing the calorie content and increasing the prebiotic capacities [11]. The use of inulin in food industry is based on its properties as a sugar replacer, fat replacer and texture modifier [12]. Inulin as a functional food was investigated in bakery products, confectionery products, ice cream and low-fat yogurt [13]. It is known that incorporation of dietary fibers into bakery products can modify the obtained product including reducing loaf time, increasing firmness and prolong freshness [14]. According to beneficial health and nutritive effects, Jerusalem artichoke containing inulin as a natural dietary fiber could be a valuable component of food products [11].

The objective of this study was to make wheat bread enriched by Jerusalem artichoke and describe its organoleptic properties, nutritional and caloric value, microbiological safety, glycemic index (GI) and glycemic load (GL) values.

\section{Materials and Method}

The bread was made from yeast dough that consisted of $75 \%$ wheat flour and $25 \%$ of J. artichoke tubers powder. The dough formulation is shown in Table 1.

\subsection{Determination of Nutritional Value}

Moisture and dry matter content were determined by AOAC method [15], total carbohydrates content according 
to Anthrone method [16], protein content was measured by standard Kjeldahl method [17] and amount of lipids was obtained by method described by Trajković J et al. [18]. Quantity of dietary fiber was determined by rapid enzymatic assay of dietary fiber in food products [19]. The parameters of nutritional value were expressed as ger $100 \mathrm{~g}$ of analyzed bread (\%). Caloric value of analyzed bread was calculated by the following standard equation:

$$
\begin{aligned}
\text { Kcal }= & 4 \times\left(\begin{array}{l}
\% \text { protein } \\
+\% \text { total carbohydrates content }
\end{array}\right)[20] \\
& +9 \times(\% \text { lipids }) .
\end{aligned}
$$

Table 1. Formulation of bread dough

\begin{tabular}{lc}
\multicolumn{2}{c}{ Table 1. Formulation of bread dough } \\
\hline Ingredients & Content (g) \\
\hline J. artichoke tubers powder & 175 \\
Wheat flour & 525 \\
Water & 650 \\
Yeast & 10 \\
Sugar & 5 \\
Salt & 5 \\
\hline
\end{tabular}

\subsection{Testing of Microbiological Safety}

Microbiological analyzes were performed according to the national regulation of the methods for microbiological analysis of foodstuffs [21]. This study included testing for presence of Salmonella sp. in $25 \mathrm{~g}$ of sample, Staphylococcus aureus and sulfate-reducing Clostridiae sp. in $0.01 \mathrm{~g}$ of sample, Proteus sp. and Escherichia coli in $0.001 \mathrm{~g}$ of bread sample.

\subsection{Determination of Glycemic Index and Glycemic Load}

The clinical study was conducted by application of internationally recognized Glycemic index methodology, according to the FAO/WHO protocol. Ten healthy volunteers (4 males and 6 females) aged between 21 and 56 years, body mass index $24.01 \pm 4.09 \mathrm{~kg} / \mathrm{m}^{2}$ (BMI $\left.\pm \mathrm{SD}\right)$ participated in the study. All participants signed consent form prior to the participation. The study was approved by Ethics Committee of Faculty of Medical Sciences, Kragujevac, Serbia. The inclusion criteria for participants were: normoglycemia $(<6.1 \mathrm{mmol} / \mathrm{l})$, not being on a diet, not being allergic to any of bread ingredients (wheat or J. artichoke). Exclusion criteria for subjects were any type of diabetes or glucose intolerance diagnosed prior to the study, drug treatment that affects glycemia and presence of chronic disease. Study subjects consumed reference food (50 g of glucose dissolved in $250 \mathrm{ml}$ water) and test food (piece of Jerusalem artichoke bread contained $50 \mathrm{~g}$ of available carbohydrates) during 10-15 minutes, with oneweek washout period between testing days. The reference food was tested three times at each subject in order to reduce variability of glucose tolerance. Glycemia was measured in capillary blood prior to the reference and test food consumption (0 min) and 15, 30, 45, 60, 90 and 120 minutes after ingestion of the food. Glucose responses elicited by consumption of test and reference food were expressed as incremental area under glycemia vs. time (0120min) curve (IAUC), calculated geometrically. Glycemic index for each subject was calculated by expressing each subject's IAUC after ingestion of the test food as a percentage of the same subject's mean reference IAUC. GI value of the test food was calculated as the mean value of all GI values obtained for all subjects $[22,23]$. Glycemic load was calculated on the basis of GI value of GI was multiplied by quantity of carbohydrates available in serving size / 100 [24]. GL was calculated for serving size of $30 \mathrm{~g}$ because according to Foster - Powell et al. International table for GI and GL values, usual serving size for wheat flour bread was $30 \mathrm{~g}$ [25].

\section{Results}

The bread enriched with J. artichoke was well baked, of regular shape, having dark brown crumb and slight smell and taste characteristic for J. artichoke.

Nutritional characteristics of analyzed bread were: $41.64 \%$ of water, $58.36 \%$ of dry matter, $0.27 \%$ of lipids, $8.25 \%$ of proteins, $47.64 \%$ of carbohydrates and $6.15 \%$ of dietary fiber. Caloric value of bread with J. artichoke was $226 \mathrm{Kcal} / 100 \mathrm{~g}$ of bread.

The results of microbiological analysis did not show bacterial or fungal contamination. None of the tested bacteria were isolated: Salmonella sp., Staphylococcus aureus, sulfate-reducing Clostridiae sp., Proteus sp. and Escherichia coli.

The obtained values for glycemic index and glycemic load were 53.70 and 7.67, respectively. The both GI and GL belong to the category of low values.

\section{Discussion}

Aromatic odor and specific taste limit the consumption of fresh J. artichoke. The bread made from $75 \%$ of wheat flour and $25 \%$ of J. artichoke tubers powder retained slight specific smell and taste of J. artichoke, but due to good organoleptic properties of a wheat bread could be accepted better for consumption then fresh tubers J. artichoke.

The obtained values for glycemic index and glycemic load were 53.70 and 7.67, respectively. According to Brand - Miller classification, GI value below 55 is considered as low, $56-69$ as medium and above 70 as high [26]. The GL values are classified as high $(>20)$, medium (11-19) and low $(<10)$ [27]. Bread with J. artichoke content belongs to category of low GI and GL food (GI = 53.70 and GL = 7.67). The literature data showed that the most of the wheat products, as a usual source of carbohydrates in diet, belong to high glycemic index food [28]. Although, there were studies on wheat bread enriched with J. artichoke, the determination of GI or GL for such product has not been reported. Amount of J. artichoke powder caused decrease of GI value for tested bread, considering that the literature GI value for wheat bread is 70-87. On the basis of International table of glycemic index and glyceamic load values which lists GL values 10-15 for different bread products from wheat flour, we may conclude that obtained value for tested bread of GL = 7.67 indicates that addition of J. artichoke decreased also the GL value of tested bread [25].

As numerous studies confirmed linkage between diet and chronic diseases (diabetes, cardiovascular diseases, and cancer), nutritional education could be useful for health - promoting habits that may prevent diseases [29]. 
Concept of GI and GL could be an important nutrition strategy in prevention and management of chronic diseases. Long - term consumption of high GI and GL food is associated with an increased risk of developing overweight and obesity, glucose intolerance and cardiovascular diseases. Long - term consumption of high GI and GL food is associated with an increased risk of developing overweight and obesity, glucose intolerance and cardiovascular diseases. Consumption of high GI and GL food have increased diabetes risk for $16 \%$ and $20 \%$, respectively [30]. Introducing values of GI and GL in nutritional education could be good strategy in prevention and management of chronic diseases [9]. Diet with low GI and GL improves prevention of metabolic and cardiovascular diseases [31]. Decreasing GI of diet improves glycemic control. Thomas and Elliott reported significant decrease in \% HbA1c levels in the group on low GI diet compared with control group [32].

Consumption of inulin - containing products has major health benefits for diabetic patients, mineral absorption from colon and promoting healthy intestinal microflora [1, $6,7,8]$. Addition of different sources of inulin to bread was studied earlier. In wheat and wheat/rice bread inulin lowered caloric value and increased dietary fiber content [33]. Bread enriched with J. artichoke powder had improved sensory quality in comparison to bread with addition of commercialy available inulin [34]. Therefore, since $\mathrm{J}$. artichoke is a source of inulin we conclude that on the basis of obtained results (acceptable organoleptic and nutritional properties and GI and GL vales) it would be justified to extend further characterization of this bread on inulin content.

\section{Conclusion}

This study reports characterization of originally formulated bread from wheat flour enriched with $25 \%$ of $\mathrm{J}$. artichoke with no additives. The bread showed optimal nutritional and caloric value, low GI and low GL values. Considering the rising incidence of chronic diseases and need for development of new food products with health promoting effects, it seems that incorporation of $\mathrm{J}$. artichoke in wheat bread is a promising attempt. Further research should be carried on this formulation targeting its content of inulin and possible health benefits of its intake.

\section{Acknowledgment}

The authors would like to express gratitude to Ministry of Education and Science of the Republic of Serbia for Grant No. 175014.

\section{Statement of Competing Interests}

The authors declare that there is no conflict of interest.

\section{References}

[1] Kays, S.J, Nottingham, S.F, Biology and Chemistry of Jerusalem Artichoke, Helianthus tuberosus L., Taylor \& Francis Group, New York, 2007.
[2] Van Loo, J., Coussement, P., De Leenheer, L., Hoebregs, H., Smits, G, "On the presence of inulin and oligofructose as natural ingredients in the Western diet”, Crit Rev Food Sci Nutr, 35, 525552, 1995.

[3] Cieslik, E, "Mineral content of Jerusalem artichoke new tubers", Zesk Nauk AR Krak, 342, 23-30, 1998.

[4] Roberfroid, M.B, "Concepts in functional foods: the case of inulin and oligofructose", J Nutr, 129, 1398-1401, 1999.

[5] Watzl, B., Girrbach, S., Roller, M, "Inulin, oligofructose and immunomodulation”, Br J Nut, 93, 49-55, 2005.

[6] Kaur, N., Gupta, A.K, "Applications of inulin and oligofructose in health and nutrition”, J Biosci, 27(7), 703-714, 2002.

[7] Meyer, D. and Stasse-Wolthuis, M, "Inulin and bone health", Cur Top Nutraceutical Res, 4(3- 4), 211-226, 2007.

[8] Menne, E., Guggenbuhl, N., Roberfroid, M, "Fn-type chicory inulin hydrolysate has a prebiotic effect in humans" J Nutr, 130(5), 1197-1199, 2000.

[9] Wong, J.M.W., Jenkins, D.J, "Carbohydrate Digestibility and Metabolic Effects”, J Nutr, 37, 2539S-2546S, 2007.

[10] Miremadi, F. and Shah, N.P, "Applications of inulin and probiotics in health and nutrition", Int Food Res J, 19(4), 13371350, 2012.

[11] Murphy, O, "Non-polyol low-digestible carbohydrates: food applications and functional benefits”, Br J Nutr, 85(1), S47-S53, 2001.

[12] Meyer, D., Bayarri, S., Tarrega A, et al., "Inulin as a texture modifier in dairy products”, Food Hydrocoll, 25(8), 1881-1890, 2011.

[13] Kip, P., Meyer, D., Jellema, R.H, "Inulins improve sensoric and textural properties of low-fat yoghurts“ Int Dairy J, 16, 1098-1103, 2006.

[14] Elleucha, M., Bedigian, D., Roiseux, O, et al., "Dietary fibre and fibre-rich by-products of food processing: characterisation, technological functionality and commercial applications: A review” Food Chem, 124(2), 411-421, 2011.

[15] Williams, S, Official methods of analysis, Association of Official Analytical Chemists, Washington DC, 1999.

[16] Hedge, J.E, and Hofreiter, B.T, Carbohydrate Chemistry, Academic Press, New York, 1962.

[17] Williams, S, Official methods of analysis, Association of Official Analytical Chemists, Washington DC, 1984.

[18] Trajković, J., Mirić, M., Baras, J., Šiler, S, Analize životnih namirnica, Tehnološko- metalurški fakultet, Beograd, 1983.

[19] Asp, N.G., Johansson, C.G., Hallmer, H. and Siljestrom, M, "Rapid enzymatic assay of insoluble and soluble dietary fiber", $J$ Agric Food Chem, 31, 476 - 482, 1983.

[20] Stanimirovic, S, Bromatologija, Farmaceutski fakultet Univerziteta u Beogradu, zavod za bromatologiju, Beograd, 1988.

[21] Official Gazette of SFRY. Methods of microbiological analysis of foodstuff $\left(\mathrm{N}^{0} 25 / 80\right)$.

[22] Wolever, T.M, Brand-Miller, J.C, Abernethy, J et al. "Measuring the glycemic index of foods: interlaboratory study", Am J Clin Nutr, 87(1), 247S-257S, 2008.

[23] FAO, Carbohydrates in human nutrition: Report of a Joint FAO/WHO Expert Consultation, FAO Food and Nutrition Paper, 1997.

[24] Monro, J.A, Shaw, M, "Glycemic impact, glycemic glucose equivalents, glycemic index, and glycemic load: definitions, distinctions, and implications”, Am J Clin Nutr, 87(1), 237S-243S, 2008.

[25] Foster-Powell, K., Holt, S.H.A, Brand-Miller, J.C, "International Table of glycemic index and glyceamic load values”, Am J Clin Nut, 76, 5-56, 2002.

[26] Brouns, F., Bjorck, I., Frayn, K.N. et al. "Glycaemic index methodology”, Nutr Res Rev, 18, 145-71, 2005.

[27] Lin, A.M.H, Wu, M.C, Lu, S, Lin, J, "Glycemic index, glycemic load and insulinemic index of Chinese starchy food", World $J$ Gastroenterol, 16(39), 497-499, 2010.

[28] Kumar, S.B, Prabhasankar, P, "Low glycemic index ingredients and modified starches in wheat based food processing: A review“, Trends Food Sci Tech, 35, 32-41, 2014.

[29] Gonçalves, R.C.E and Dullius, J, "Glycemic acute changes in type 2 diabetics caused by low and high glycemic index diets", Nutr Hosp, 26(3), 546-552, 2011.

[30] Dong, J.Y, Zhang, L, Zhang, Y.H, Qin, L.Q, “Dietary glycaemic index and glycaemic load in relation to the risk of type 2 diabetes: 
a meta-analysis of prospective cohort studies”, Br J Nutr, 106(11), 1649-1654, 2011.

[31] Marangoni, F, Poli, A, "The glycemic index of bread and biscuits is markedly reduced by the addition of a proprietary fiber mixture to the ingredients”, Nutr Metab Cardiovas, 18, 602-605, 2008.

[32] Thomas, D.E, Elliott, E.J, "The use of low-glycaemic index diets in diabetes control”, Br J Nutr 104(6), 797-802, 2010.
[33] Meyer, D, Peters, B, "Enhancing the nutritional value of bread with inulin”, Agro Food Ind Hi Tec, 20(3), 48-50, 2009.

[34] Praznik, W, Cieślik, E, Filipiak-Florkiewicz, A, "Soluble dietary fibres in Jerusalem artichoke powders: composition and application in bread”, Nahrung, 46(3), 151-157, 2002. 